\title{
A clinically challenging diagnosis of adenoma of the retinal pigment epithelium presenting with clinical features of choroidal hemangioma
}

This article was published in the following Dove Press journal:

Clinical Ophthalmology

24 March 2012

Number of times this article has been viewed

\author{
Sohei Nakamura' \\ Naofumi Hikita ${ }^{2}$ \\ Ryoji Yamakawa' \\ Fukuko Moriya ${ }^{3}$ \\ Hirohisa Yano ${ }^{3}$ \\ Emiko Furusato ${ }^{4}$ \\ J Douglas Cameron ${ }^{5}$ \\ Elisabeth J Rushing ${ }^{4}$ \\ 'Department of Ophthalmology, \\ Kurume University School of \\ Medicine, Kurume, ${ }^{2}$ Fukubiru Hikita \\ Eye Clinic, ${ }^{3}$ Department of Pathology, \\ Kurume University School of \\ Medicine, Kurume, Fukuoka, Japan; \\ ${ }^{4}$ Department of Neuropathology and \\ Ophthalmic Pathology, Armed Forces \\ Institute of Pathology, Washington, \\ DC, ${ }^{5}$ Departments of Ophthalmology \\ and Laboratory Medicine and \\ Pathology, University of Minnesota, \\ Minneapolis, USA
}

Background: Adenoma of the retinal pigment epithelium (RPE) is a rare intraocular tumor that can simulate other pigmented tumors such as choroidal melanoma. We report a case of non-pigmented adenoma of the RPE initially diagnosed as choroidal hemangioma.

Case report: A 42-year-old woman presented to Kurume University Hospital in November 1992 with an orange-yellow tumor nasal to the optic disc in the left fundus. The tumor was $9.0 \times 9.0 \mathrm{~mm}$ in diameter, $6.0 \mathrm{~mm}$ thick, and was characterized by high intensity on T1-weighted magnetic resonance imaging (MRI), low intensity on T2-weighted MRI, and enhancement on gadolinium MRI. Fluorescein angiography revealed early hypofluorescence and late hyperfluorescence of the tumor and retinal feeder vessels. By April 1996, exudate had developed around the tumor margins. The patient was treated with external beam radiation therapy (20 Gy) in July 1996, but the tumor did not diminish in size. Subsequently, she developed extensive loss of vision due to total retinal detachment. Accordingly, her left eye was enucleated in June 2005 because of severe ocular pain due to absolute glaucoma. Histopathological examination indicated that the tumor was contiguous with the normal surrounding RPE and was composed of cords and tubules of mostly non-pigmented spindle-shaped cells with round to oval nuclei and a small amount of cytoplasm containing melanin granules. The tumor cells were immunoreactive for vimentin, S-100 protein, and cytokeratin 18 . The final diagnosis was adenoma of the RPE.

Conclusion: Adenoma of the retinal pigment epithelium may be associated with incompetent vessels leading to serous retinal detachment and extensive visual loss, and may exhibit clinical characteristics similar to choroidal hemangioma.

Keywords: adenoma, choroidal hemangioma, histopathology, retinal pigment epithelium

\section{Introduction}

Neoplastic lesions of the retinal pigment epithelium (RPE) are exceedingly rare, although benign reactive proliferations and hyperplasia are frequent in the setting of trauma and inflammation. ${ }^{1}$ Most neoplasms of the RPE are deeply pigmented and are likely to extend into the substance of the retina resulting in exudative retinal detachment. In most cases, it is difficult to clinically differentiate adenomas of the RPE from malignant melanoma. Definitive diagnosis relies on histopathologic examination of the enucleated eye. Although adenomas of the RPE can cause visual loss, ${ }^{2}$ they are generally benign and do not metastasize. Once the diagnosis is confirmed, adenomas of the RPE can be safely observed. However, there have been few reports of this entity where the clinical diagnosis is difficult. We report a case of non-pigmented adenoma of the RPE with long-term follow-up.
Correspondence: Sohei Nakamura

Department of Ophthalmology, Kurume University School of Medicine,

67 Asahi-machi, Kurume,

Fukuoka 830-00II, Japan

$\mathrm{Tel}+8 \mathrm{I} 942317574$

Fax +8I 942370324

Email nakamura_souhei@kurume-u.ac.jp 


\section{Case report}

A 42-year-old woman complaining of eye fatigue presented to Kurume University Hospital in November 1992. Except for chronic hepatitis and uterine myoma, her medical history was unremarkable. At the age of 15 years, she experienced minor trauma of the left eye; however, additional details were not available. Her best-corrected visual acuity (BCVA) in both eyes was 1.0. The right eye was normal and no abnormalities were noted in the anterior segment and media of the left eye. In the left posterior segment, there was an orange-yellow, partially pigmented mass nasal to the optic disc (Figure 1A). The mass was initially hypofluorescent, then exhibited late hyperfluorescence (Figure 1B and C) with fluorescein angiography (FA). No distant metastases were detected with computed tomography (CT). The tumor was considered primary within the eye and was diagnosed as choroidal hemangioma to be observed periodically.

In April 1996, her BCVA was 1.0 in both eyes. Hard exudates and exudative retinal detachment were present in the affected eye and tumor enlargement was documented (Figure 2A). FA of the tumor showed early hypofluorescence, late hyperfluorescence, and exudation (Figure 2B). Indocyanin green angiography revealed intratumoral hyperfluorescence and the presence of intratumoral feeder vessels that seemed to anastomose with retinal vessels (Figure 2C). Ultrasonography of the tumor demonstrated medium to high internal reflectivity. B-scan ultrasonography showed a solid, elevated mass, which measured $9.0 \times 6.0 \mathrm{~mm}$, adjacent to the optic nerve with surrounding exudative retinal detachment (Figure 3A). CT confirmed the presence of an attenuating soft tissue mass in the posterior segment (Figure 3B). On MRI, the tumor showed high intensity on T1-weighted images (Figure 4A) and low intensity on T2-weighted images (Figure 4B) with gadolinium enhancement (Figure 4C).

In April 1997, BCVA in her left eye decreased to 0.03 due to exudative retinal detachment. The patient consulted another institution for a second opinion, where the working diagnosis was choroidal hemangioma. In June 1997, she underwent external beam radiation therapy (20 Gy) because the position and size of the tumor limited the use of laser photocoagulation or cryotherapy. The tumor did not respond to radiation therapy and the exudation around the tumor was unaffected by treatment. In May 1998, the exudative retinal detachment progressed to total retinal detachment and visual acuity in the left eye decreased to light perception. In December 1999, the patient's vision was further reduced to no light perception. The development of posterior synechiae and secondary cataract prevented the view of the fundus;
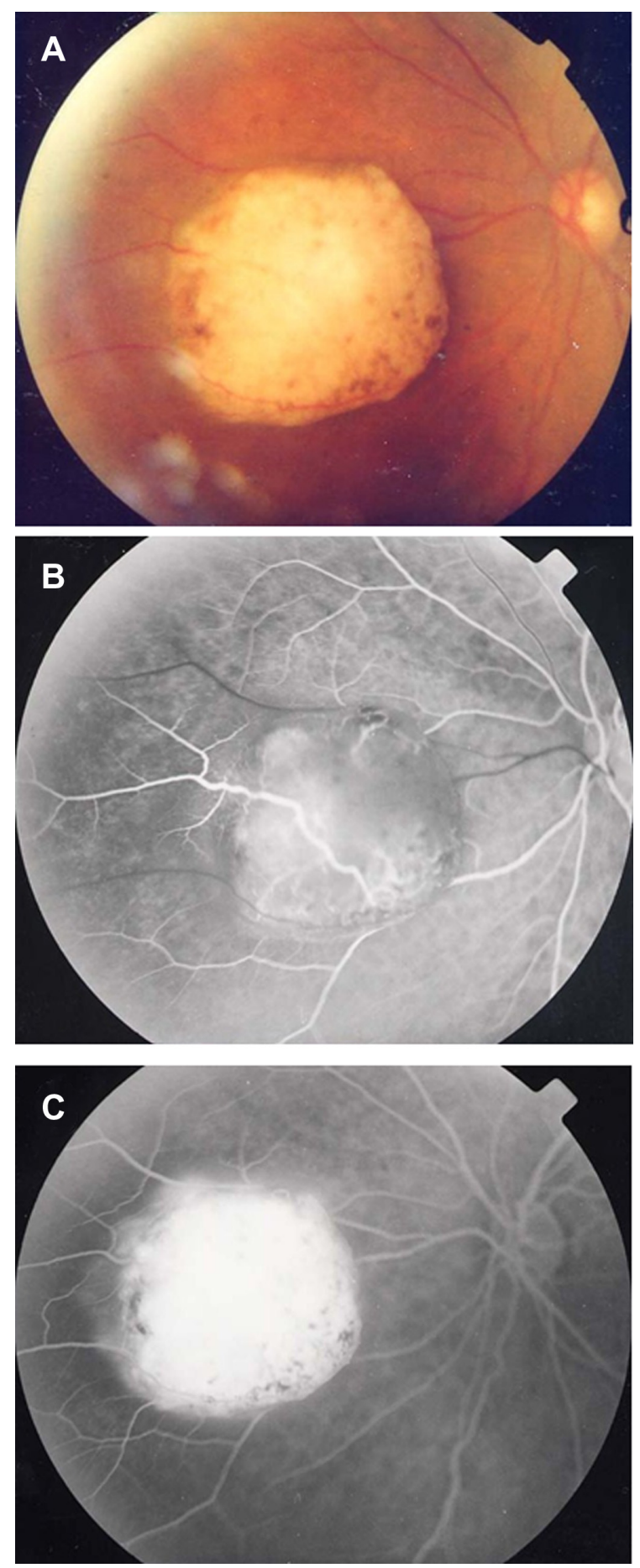

Figure I Fundus photograph and fluorescein angiogram taken in November 1992. (A) Fundus photograph of the left eye showing an orange-yellow retinal tumor nasal to the optic disc. (B) Early phase showing hypofluorescence of the mass. (C) Late phase showing hyperfluorescence of the mass.

however, the tumor was observed with ultrasonography. The tumor size remained stable. In March 2005, the patient developed severe ocular pain associated with elevated intraocular pressure. Although laser iridotomy was performed to treat neovascular glaucoma with iris bombe, intraocular pressure 

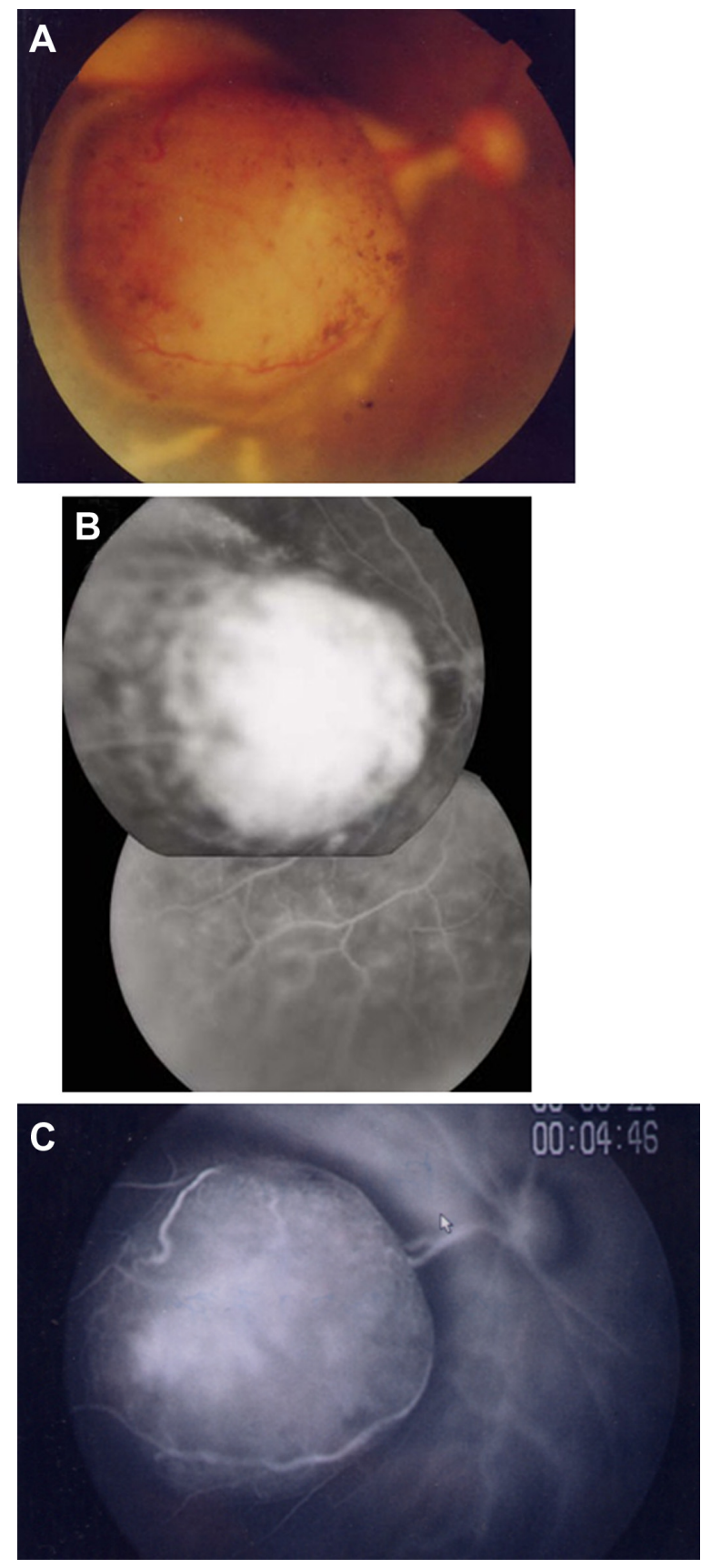

Figure 2 Fundus photograph, fluorescein angiogram, indocyanin green angiogram taken in April 1996. (A) Fundus photograph showing enlargement of the mass, hard exudates, and exudative retinal detachment. (B) Fluorescein angiogram showing hyperfluorescence of the tumor and exudative retinal detachment. (C) Indocyanin green angiogram showing intratumoral hyperfluorescence and the presence of intratumoral feeder vessels that seemed to be anastomosing with retinal vessels.

remained elevated. After obtaining written consent from the patient, her left eye was enucleated in June 2005.

\section{Histopathological findings}

The enucleated eye was immediately fixed in $10 \%$ buffered formalin and sectioned along the anterior-posterior axis. A well-circumscribed white mass measuring $8.0 \times 5.0 \mathrm{~mm}$
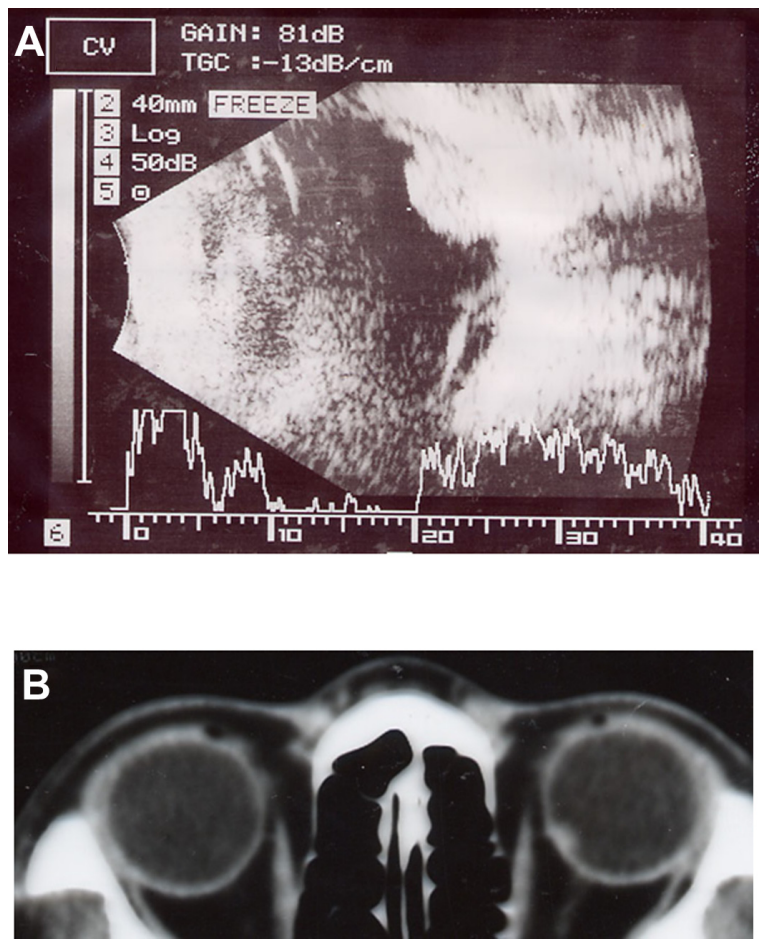

Figure 3 B-scan and A-scan ultrasonogram, computed tomography taken in April 1996. (A) B-scan ultrasonogram showing a solid mass measuring about $9.0 \times 6.0 \mathrm{~mm}$ with exudative retinal detachment. A-scan ultrasonogram of the tumor, demonstrating medium to high internal reflectivity. (B) Computed tomography showing tumor located in the posterior pole.

was present on the nasal side of the optic disc without apparent extrascleral extension (Figure 5).

The well-circumscribed tumor arose at the level of the RPE, and did not invade the choroid (Figure 6A and B). The mass was composed of cords and tubules of mostly nonpigmented epithelial cells with round to oval nuclei and a small amount of cytoplasm containing melanin granules. Focally, tumor cells showed vacuolated pattern and basement membrane material surrounded tumor cells (Figure 6C). No mitotic figures were seen.

The tumor cells showed immunoreactivity to vimentin (Figure 7A) and S-100 protein (Figure 7B). The tumor cells showed focal immunoreactivity to cytokeratin 18 (Figure 7C), but were nonreactive to AE1/AE3, GFAP, HMB-45, and Melan A. The case was diagnosed as adenoma of the RPE based on the clinical (FA, ultrasonography, CT, MRI) and microscopic features, including the immunohistochemical profile.

\section{Discussion}

Adenoma of the ciliary pigment epithelium is a rare intraocular tumor that is extremely uncommon in the RPE. ${ }^{3}$ On the basis of clinical criteria alone it is difficult to 

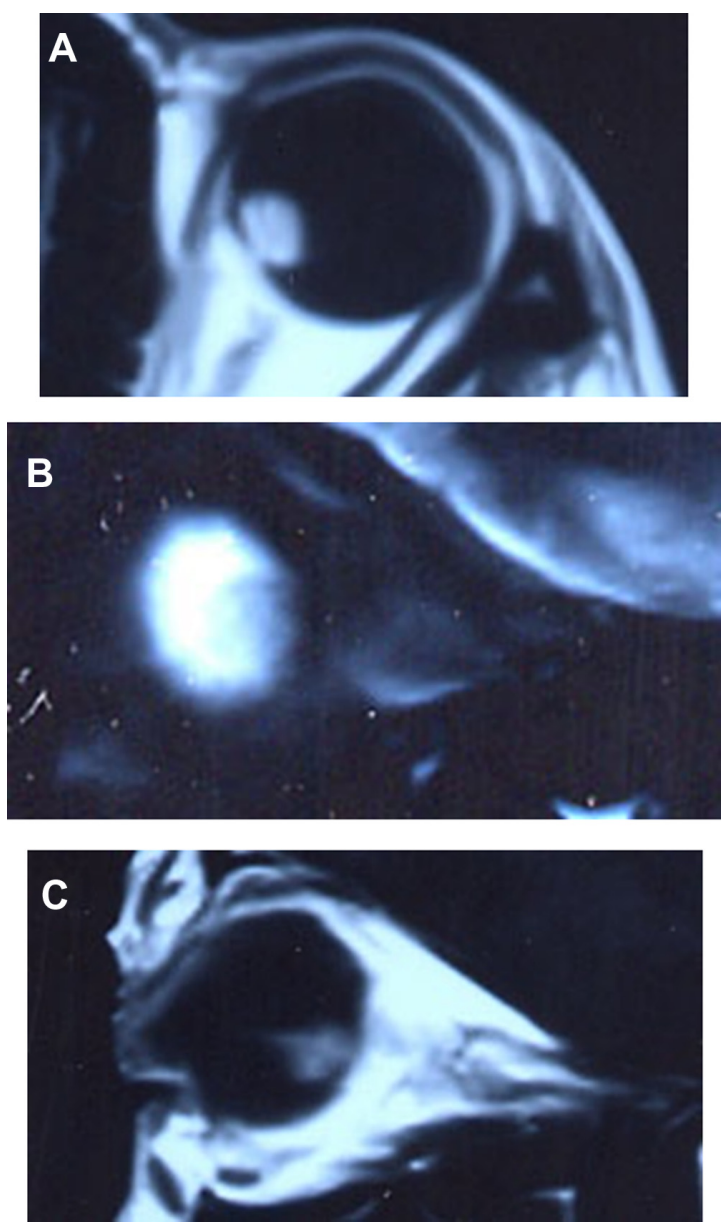

Figure 4 Magnetic resonance image taken in April 1996. (A) TI-weighted axial magnetic resonance image of the tumor showing high intensity. (B) T2-weighted sagittal magnetic resonance image of the tumor showing low intensity. (C) Gadoliniumenhanced sagittal magnetic resonance image of the tumor showing enhancement.

differentiate adenoma of the RPE from malignant choroidal melanoma. ${ }^{2-7}$ Isolated cases of adenoma of the RPE that simulate a juxtapapillary choroidal neovascular membrane, ${ }^{8}$ a melanocytoma, ${ }^{9,10}$ and hyperplasia of the $\mathrm{RPE}^{11}$ have been documented, but little is known about the clinical course of

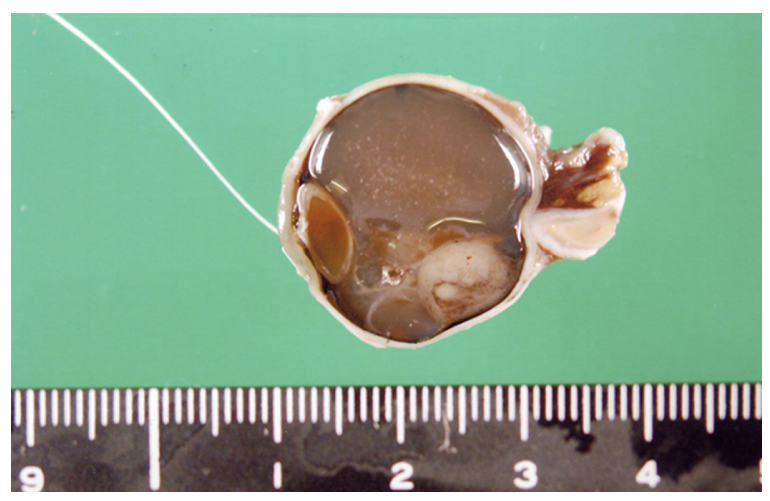

Figure 5 Gross photograph of sectioned eye showing tumor measuring about $8.0 \times 5.0 \mathrm{~mm}$ located on the nasal side of the optic disc.
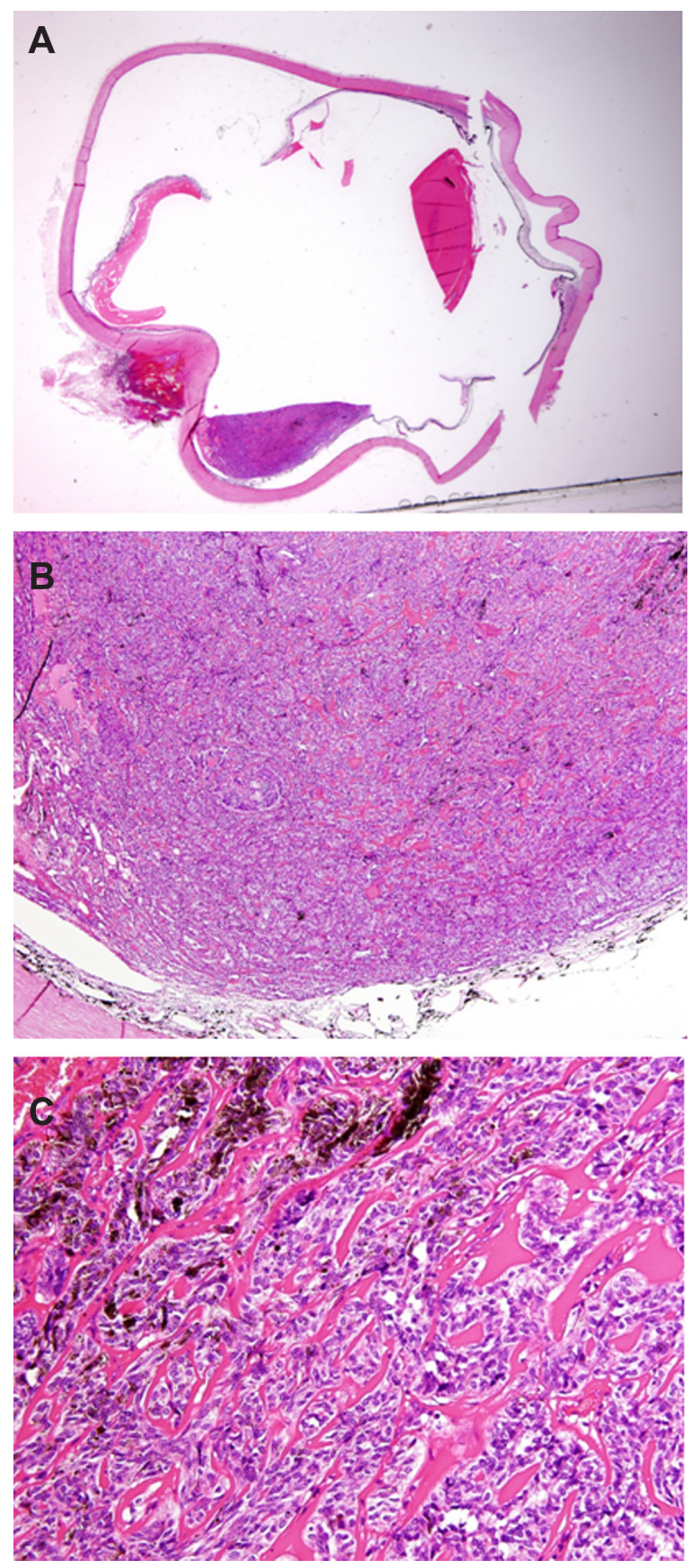

Figure 6 Histopathology. (A) Mass adjacent to choroid in the posterior pole (hematoxylin and eosin stain; original magnification $4 \times$ ). (B) Partially pigmented tumor cells (hematoxylin and eosin stain; original magnification $32 \times$ ). (C) Tumor cells arising from RPE surrounded by basement membrane (hematoxylin and eosin stain; original magnification $160 \times$ ).

adenoma of the RPE with these types of presentations. The current case, which was initially diagnosed as a choroidal hemangioma, progressed very slowly.

Choroidal melanoma typically shows acoustic hollowness and choroidal excavation with B-scan ultrasonography and mottled hyperfluorescence in the vascular filling phases with FA. In contrast, the present case was only slightly 

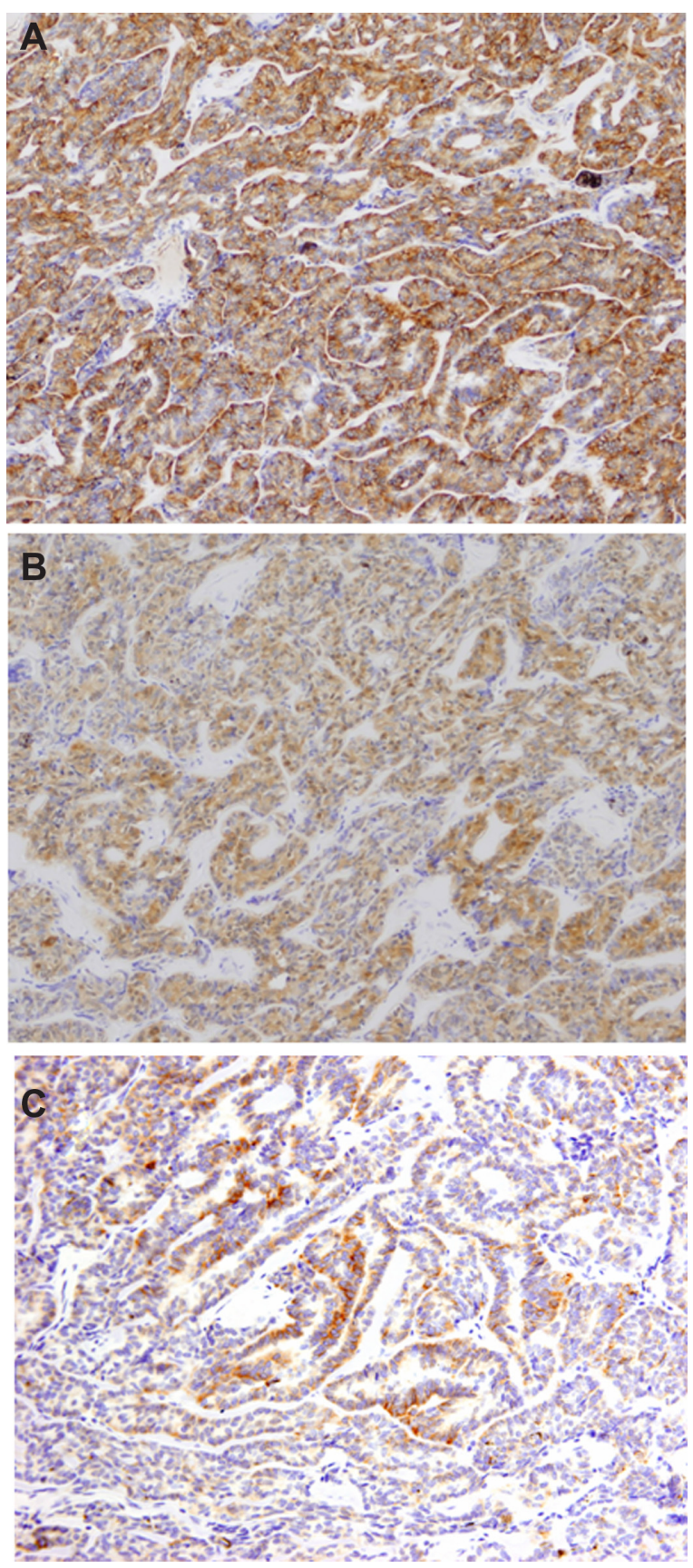

Figure 7 Immunohistochemical features. (A) Immunohistochemical staining of tumor cells showing positivity for vimentin and (B) S-100 protein. (C) The tumor cells immunoreact with cytokeratin 18.

pigmented but lacked acoustic hollowness and choroidal excavation characteristic of choroidal melanoma. ${ }^{12}$ The consideration of choroidal melanoma was considered less likely given the color of the tumor and the long stable clinical course without evidence of metastatic disease.

Retinal hemangioblastoma may be a component of von Hippel-Lindau syndrome where the lesion typically appears as a reddish-pink tumor in the peripheral retina or on the optic disc. Development of a retinal tumor after
40 years of age is rare. ${ }^{13}$ Intraretinal and subretinal exudation and feeding and draining blood vessels are characteristic features. ${ }^{13}$ In this entity, FA shows rapid hyperfluorescence of the mass in the arterial phase. Of note, our case did not show hyperfluorescence in the arterial phase, and systemic evaluation of our patient showed no evidence of von Hippel-Lindau syndrome. The diagnosis of retinal hemangioblastoma was thus excluded in our case.

Choroidal hemangioma generally shows high internal reflectivity with A-scan ultrasonography, acoustic solidity with B-scan ultrasonography, hyperintensity compared to the vitreous on T1-weighted images, and isointensity compared to the vitreous on T2-weighted MRI. ${ }^{14}$ The current tumor with elevated and well defined margins and orangeyellow color differed from the findings of typical choroidal hemangioma.

Adenoma of the RPE is described as abruptly elevated masses that can induce retinal exudation and exudative retinal detachment. In addition, they show acoustic solidity with B-scan ultrasonography and high internal reflectivity with A-scan ultrasonography. ${ }^{2,3,11}$ With the exception that the tumor was non-pigmented, the findings in our case were consistent with the clinical features of adenoma of the RPE. FA of the tumors of the RPE tends to show prominent feeder vessels in arterial-phase, early hypofluorescence, and late hyperfluorescence. At the first visit, FA of our patient showed retinal feeder vessels in arterial-phase and late hyperfluorescence (Figures 1B and C). Adenoma of the RPE has been reported to respond poorly to radiotherapy. ${ }^{6}$ Our case was treated with radiotherapy in June 1997, but did not respond to therapy, and the patient eventually required enucleation of the left eye.

Histopathologically, adenoma of the RPE appears to arise from the adjacent normal RPE. ${ }^{2}$ It is reported that an adenoma of the RPE rests upon Bruch's membrane and can focally invade the choroid, sensory retina, and vitreous. . $^{1,2,45}$ There was no invasion of the choroid in our case (Figure 6B).

Microscopically, RPE adenoma is composed of cords and tubules of RPE cells separated by periodic acid-Schiff-positive basement membrane. ., $, 5,7-9,11$ Three basic patterns are recognized, including solid growth in which tumor cells are separated by periodic acid-Schiff-positive basement membrane, a vacuolated pattern characterized by prominent vacuoles, and a combined pattern. ${ }^{2}$ Vacuolated tumors are located in the more anterior region of the RPE, and solid tumors are more posteriorly located. ${ }^{2}$ The tumor in our case was composed of cords and tubules of tumor cells separated by basement membrane, consistent with the solid pattern of adenoma of 
the RPE (Figure 6C). Of note, tumor cells in an adenoma of the RPE are not always pigmented. ${ }^{7}$ In our case, most of the tumor cells were non-pigmented (Figure 6B and C).

Because adenoma of the RPE is such a rare tumor, its immunohistochemical features are not well known. In general, adenoma of the RPE is negative for HMB- $45,{ }^{15}$ in contrast to malignant melanoma. However, there is a single report of adenoma of the RPE that was positive for HMB-45. ${ }^{11}$ Therefore, it is important to employ a panel of immunohistochemical stains and interpret the findings in combination with clinical features.

Here we have reported a rare case of nonpigmented adenoma of the RPE to heighten awareness of this uncommon entity. It is particularly important to differentiate this entity from uveal melanoma.

\section{Disclosure}

The authors report no conflicts of interest in this work.

\section{References}

1. Font RL, Zimmerman LE, Fine BS. Adenoma of the retinal pigment epithelium: histochemical and electron microscopic observations. Am J Ophthalmol. 1972;73(4):544-554.

2. Shields JA, Shields CL, Gündüz K, Eagle RC Jr. Neoplasms of the retinal pigment epithelium: the 1998 Albert Ruedemann, Sr, memorial lecture, Part 2. Arch Ophthalmol. 1999;117(5):601-608.

3. Shields JA, Shields CL. Epithelioma (adenoma) of the retinal pigment epithelium. In: Shields JA, Shields CL, editors. Intraocular Tumors: An Atlas and Textbook. 2nd ed. Philadelphia, PA: Lippincott Williams and Wilkins; 2008:466-468.

4. Shields JA, Melki T, Shields CL, Eagle RC Jr, Singh AD. Epipapillary adenoma of the retinal pigment epithelium. Retina. 2001;21(1):76-78.
5. Loose IA, Jampol LM, O'Grady R. Pigmented adenoma mimicking a juxtapapillary melanoma. Arch Ophthalmol. 1999;117(1):120-122.

6. Finger PT, McCormick SA, Davidian M, Walsh JB. Adenocarcinoma of the retinal pigment epithelium: a diagnostic and therapeutic challenge. Graefes Arch Clin Exp Ophthalmol. 1996;234(Suppl 1): S22-S27.

7. Zhang P, Feng G, Yue T, Lin J, YiY, Pang Y. Pathological, ultrastructural and immunohistochemical observations of retinal pigment epithelium. Yan Ke Xue Bao. 2001;17(3):168-172.

8. Shields JA, Materin M, Shields CL, Eagle RC Jr. Adenoma of the retinal pigment simulating a juxtapapillary choroidal neovascular membrane. Arch Ophthalmol. 2001;119(2):289-292.

9. Shields JA, Eagle RC Jr, Shields CL, De Potter P. Pigmented adenoma of the optic nerve head simulating a melanocytoma. Ophthalmology. 1992;99(11):1705-1708.

10. Blodi FC, Reuling FH, Sornson ET. Pseudomelanocytoma at the optic nervehead: An adenoma of the retinal pigment epithelium. Arch Ophthalmol. 1965;73:353-355.

11. Heegaard S, Larsen JN, Fledelius HC, Prause JU. Neoplasia versus hyperplasia of the retinal pigment epithelium. A comparison of two cases. Acta Ophthalmol Scand. 2001;79(6):626-633.

12. Shields JA, Shields CL. Posterior uveal melanoma: diagnostic approaches. In: Shields JA, Shields CL, editors. Intraocular Tumors: An Atlas and Textbook. 2nd ed. Philadelphia, PA: Lippincott Williams and Wilkins; 2008:128-129.

13. Shields JA, Shields CL. Retinal hemangioblastoma (capillary hemangioma). In: Shields JA, Shields CL, editors. Intraocular Tumors: An Atlas and Textbook. 2nd ed. Philadelphia, PA: Lippincott Williams and Wilkins; 2008:368-369.

14. Shields JA, Shields CL. Circumscribed choroidal hemangioma. In: Shields JA, Shields CL, editors. Intraocular Tumors: An Atlas and Textbook. 2nd ed. Philadelphia, PA: Lippincott Williams and Wilkins; 2008:230-232.

15. Terasaki H, Nagasaka T, Arai M, Harada T, Miyake Y. Adenocarcinoma of the nonpigmented ciliary epithelium: report of two cases with immunohistochemical findings. Graefes Arch Clin Exp Ophthalmol. 2001;239(11):876-881.
Clinical Ophthalmology

\section{Publish your work in this journal}

Clinical Ophthalmology is an international, peer-reviewed journal covering all subspecialties within ophthalmology. Key topics include: Optometry; Visual science; Pharmacology and drug therapy in eye diseases; Basic Sciences; Primary and Secondary eye care; Patient Safety and Quality of Care Improvements. This journal is indexed on Submit your manuscript here: http://www.dovepress.com/clinical-ophthalmology-journal

\section{Dovepress}

PubMed Central and CAS, and is the official journal of The Society of Clinical Ophthalmology (SCO). The manuscript management system is completely online and includes a very quick and fair peer-review system, which is all easy to use. Visit http://www.dovepress.com/ testimonials.php to read real quotes from published authors. 